\title{
Problemas não convencionais: estratégias de resolução de alunos dos anos iniciais do ensino fundamental
}

Marina de Souza Bortolucci *

Paula Cristina Chiarello**

Alessandra Rodrigues de Almeida***

* (Secretaria Municipal de Educação, Campinas, São Paulo, Brasil)

** (Secretaria Municipal de Educação, Campinas, São Paulo, Brasil)

*** (Faculdade de Educação, PUC Campinas, São Paulo, Brasil)

**** (Faculdade de Educação, PUC Campinas, São Paulo, Brasil)
Resumo: Este artigo tem como objetivo discutir a resolução de problemas como estratégia para aulas de matemática considerando três momentos: antes, durante e depois da proposta, em uma turma do $1^{\circ}$ ano e uma de $3^{0}$ ano do ensino fundamental de uma escola da rede pública do interior de São Paulo. Os dados foram produzidos a partir dos registros dos alunos e das videogravações das aulas nas quais as atividades foram realizadas. A pesquisa se desenvolveu numa perspectiva qualitativa, valorizando a descrição e análise das interações nas aulas. Os resultados indicaram que o trabalho com situações que efetivamente se configuram como problemas possui grande potencial para a aprendizagem matemática dos alunos e mostraram que a metodologia utilizada permite assegurar um ambiente de aprendizagem marcado pela relação dialógica entre professor e aluno.

Palavras-chave: Educação matemática. Ensino fundamental. Resolução de problemas. 


\section{INTRODUÇÃO}

A resolução de problemas se configura como um aspecto central do ensino e da aprendizagem da matemática escolar e pode ser compreendida como o motor do desenvolvimento da matemática e da atividade matemática (ABRANTES, 1989). Por meio do trabalho com elaboração e resolução de problemas, o aluno pode envolver-se e interessar-se pela descoberta, assim como os matemáticos o fazem, conseguindo inicialmente pensar e intuir sobre os resultados e depois prová-los (ALVARENGA; VALE, 2007).

Para Alvarenga e Vale (2007), a resolução de problemas se configura como uma forma, entre tantas outras, de colocar os alunos numa situação de "fazer matemática”, contribuindo para a motivação e redução da indisciplina. Além disso, possibilita uma relação entre a realidade e a sala de aula, favorecendo o trabalho com diferentes conceitos matemáticos ao mesmo tempo.

Consideramos que a resolução de problemas deva estar muito presente nas discussões que envolvem as aulas de matemática, principalmente nos anos iniciais do ensino fundamental. Nos últimos anos, a temática ganhou espaço nos cursos de formação, na literatura e nos documentos educacionais norteadores do trabalho do professor (ONUCHIC; ALLEVATO, 2011; NACARATO; MENGALI; PASSOS, 2009).

Porém, as inquietações dos professores sobre o assunto são muitas, uma vez que, ao vivenciar a maneira como os alunos resolvem situações-problema, observa-se que, geralmente, o foco está no algoritmo como resolução imediata, selecionando os números presentes no problema e aplicando alguma técnica das quatro operações, o que faz com que a interpretação, o raciocínio, a lógica e os processos mentais se percam. Isso talvez ocorra em razão de que, por vezes, após a exposição de um "problema” e indicada sua solução, é apresentada aos alunos uma lista de "situações-problema" com características análogas ao primeiro exposto, subentendendo que o aluno deva seguir os mesmos procedimentos. É provável, então, que a criança depreenda que não há necessidade de interpretar, mas apenas usar os registros numéricos encontrados no texto.

Tais reflexões nos levaram às análises que trazemos neste artigo e que resultam de uma investigação que objetivou discutir a resolução de problemas como estratégia de ensino-aprendizagem com turmas dos anos iniciais do ensino fundamental de duas classes de uma escola da rede pública do interior de São Paulo. Planejamos ações com o intuito de proporcionar um 
ambiente de aprendizagem que contemplasse os três momentos destacados e apresentados por Van de Walle (2009) para a resolução de problemas: o antes - planejar as situações-problema, observando se representam um desafio para o aluno; o durante - a resolução das situações-problema, registro e apresentação destas; e o depois - discussão e síntese com todas as crianças.

\section{RESOLUÇÃO DE PROBLEMAS}

Tanto as Diretrizes Curriculares da Educação Básica para o Ensino Fundamental de Campinas (CAMPINAS, 2012) quanto os Parâmetros Curriculares Nacionais (BRASIL, 1998) enfatizam que as situações-problema são fundamentais para propiciar a aprendizagem de conceitos, procedimentos e atitudes relacionados à matemática. 0 ensino, ancorado na resolução de problemas, deve possibilitar ao aluno refletir sobre diferentes estratégias, registrar e explicitar o raciocínio percorrido na resolução, discutindo diferentes formas de pensar com os colegas e o professor, tornando a aprendizagem rica e prazerosa.

A resolução de problemas contribui para que o aluno tenha a possibilidade de conviver em sala de aula com a diversidade de saberes, respeitando o outro e ampliando sua própria busca na resolução de problemas. Reconhecemos a importância da interação social em sala, posto que sem ela:

[...] a lógica da criança não se desenvolve plenamente, porque é nas situações interpessoais que ela sente-se obrigada a ser coerente. Sozinha, a criança poderá dizer e fazer o que quiser pelo prazer do momento, mas em grupo, diante de outras pessoas, sentirá a necessidade de pensar naquilo que irá dizer e fazer para que possa ser compreendida (CÂNDIDO, 2001, p. 27).

Realizamos um levantamento de situações-problema de diferentes tipos, que levassem as crianças a pensarem em diversas estratégias, para além da aplicação direta de um algoritmo. Pretendemos romper com o ensino que privilegia a proposição de problemas convencionais, compostos por dados explícitos e frases curtas, como uma tarefa para que os alunos aprendam determinado conteúdo ensinado ou apenas para identificar quais operações são apropriadas, transformando as informações do problema em linguagem matemática. Ações dessa natureza em geral conduzem ao desencadeamento de soluções padrão, nas quais a solução seja sempre numérica e única (DINIZ, 2001, p. 89).

Ao utilizar a resolução de problemas como metodologia de ensino na educação matemática, é necessário esclarecer o que se compreende efetivamente 
por problema. A maneira como esse termo vem sendo utilizado pode gerar incompreensões quanto à sua utilização nas aulas de matemática, uma vez que alunos que aparentam ter um bom desempenho escolar muitas vezes não conseguem ter o mesmo desempenho na hora de resolver verdadeiros problemas. Isso pode ocorrer em virtude da forma como essa estratégia é utilizada. Nem sempre uma tarefa que é apresentada como problema pode ser considerada como tal. Em algumas situações, a proposta feita se relaciona a exercícios repetitivos para aprender/treinar algum algoritmo ou conteúdo que acabou de ser estudado.

De acordo com os Parâmetros Curriculares Nacionais, "problema certamente não é um exercício no qual o aluno aplica, de forma quase mecânica, uma fórmula ou um processo operatório" (BRASIL, 1998, p. 43). Esse tipo de atividade gera nos alunos uma atitude passiva nas aulas. Ao perceberem que certas características acabam se repetindo, criam procedimentos padronizados para utilizar em situações semelhantes, sem nenhuma reflexão.

$\mathrm{Na}$ literatura encontramos definições para o termo problema que podem nortear o professor a escolher as situações a serem desenvolvidas com os alunos, propiciando que desenvolvam um pensamento matemático. Nesse sentido, um problema se configura como:

[...] uma situação, proposta com a finalidade educativa, que propõe uma questão matemática cujo método de solução não é imediatamente acessivel ao aluno/resolvedor ou ao grupo de alunos que tenta resolvê-la, porque não dispõe de um algoritmo que relaciona os dados e a incógnita ou de um processo que identifique automaticamente os dados com a conclusão e, portanto, deverá buscar, investigar, estabelecer relações e envolver suas emoções para enfrentar uma situação nova (VILA; CALLEJO, 2006, p. 29).

Nesta perspectiva, trabalhar a matemática por meio da metodologia de resolução de problemas é uma forma de mudar a dinâmica de sala de aula, pois os problemas são vistos como elementos que podem disparar a construção do conhecimento. Com isso, os alunos tornam-se protagonistas do processo de ensino-aprendizagem, podendo colocar-se diante de questionamentos e pensar por si próprios, utilizando seus conhecimentos, desenvolvendo o raciocínio lógico, lidando com situações novas (CÂNDIDO, 2001).

Onuchic (1999) e Onuchic e Allevato (2005) evidenciam que um problema é algo que não sabemos fazer, mas que estamos interessados em fazer. Já Van de Walle (2009) define problema como qualquer tarefa ou atividade para a qual os alunos não possuem regras prescritas ou memorizadas para sua resolução, nem a percepção de que exista um método específico para chegar à solução correta. 
BORTOLUCCI, Marina de Souza; CHIARELLO, Paula Cristina; ALMEIDA, Alessandra Rodrigues de; MEGID, Maria Auxiliadora Bueno Andrade

Outros autores, Díaz e Poblete (2001), indicam que a resolução de problemas requer a matematização de uma situação dada, que não necessariamente precisa ser numérica, mas que exige certa busca por parte do aluno para sua solução. Se for possível matematizar uma situação quase automaticamente e sem esforço, esta não se configura como um problema, mas sim como um exercício de matematização.

Outro aspecto relevante a ser destacado é que a resolução de problemas permite aos alunos dos anos iniciais explicarem o raciocínio empreendido para encontrarem uma solução. Para Boavida e Menezes (2012), de maneira epistemológica, é possível indicar que raciocinar remete a calcular. No entanto, o raciocínio é ainda utilizado para julgar, compreender, examinar, avaliar, justificar e concluir. Desse modo, em matemática não raciocinamos apenas para provar algo, mas também ao apresentar razões que justificam ideias e/ ou posicionamentos. Depreendemos então que a resolução de problemas com diferentes estruturas possibilita aos alunos raciocinar e justificar as diferentes possibilidades de solução.

Diante do exposto, no presente artigo trazemos análises de atividades relativas ao trabalho com situações-problema de diferentes tipos (STANCANELLI, 2001): problemas sem solução, rompendo com a concepção de que todo problema tem solução; problemas com mais de uma solução, possibilitando a compreensão de que um mesmo problema pode ter diferentes soluções e não apenas uma maneira correta de realizá-lo; problemas com excesso de dados, levando a criança a selecionar as informações relevantes à resolução; e problemas de lógica, cuja base não é numérica, exigindo um raciocínio dedutivo, levantamento de hipóteses, análise, busca de suposições, entre outros.

Considerando o exposto, ao professor que perspectiva trabalhar com a resolução de problemas é necessária uma compreensão clara tanto do conhecimento matemático envolvido como da forma adequada de sua utilização enquanto metodologia. Desse modo, é importante que o professor esteja atento para o fato de que o trabalho por meio da resolução de problemas requer tempo e um bom planejamento. Cabe a ele realizar a intermediação, levar o aluno a pensar sobre suas próprias estratégias, estimular o diálogo e o debate de ideias entre a turma, e propiciar condições para que os alunos desenvolvam a comunicação matemática, contribuindo significativamente para a formação destes. 
Diante de todo esse contexto em relação à resolução de problemas, consideramos fundamental que tais discussões estejam presentes na escola, visando superar a ideia de que a matemática se relaciona apenas a cálculos mecânicos ou mesmo à simples resolução de atividades do livro didático.

\section{CONTEXTO E PERCURSO METOdOLÓGICO DA INVESTIGAÇÃO}

A proposta do trabalho com problemas não convencionais era de que as crianças se vissem diante de situações desafiadoras, nas quais as perguntas não fossem desta natureza: "é de mais ou de menos?", "é de vezes ou de dividir?", “que conta tenho que fazer?”. Tencionávamos que utilizassem estratégias de interpretação e raciocínio lógico, que nem sempre necessitam das operações básicas para sua resolução.

Neste artigo, focamos as discussões sobre as produções dos alunos ao resolverem dois problemas de diferentes tipos (STANCANELLI, 2001). Por não se tratar de problemas que pressupõem respostas únicas e quantitativas, optamos por seguir a linha qualitativa de pesquisa, com análise interpretativa dos dados obtidos por meio dos registros das crianças, das observações das professoras e de discussões em sala.

A pesquisa foi desenvolvida pelas professoras-pesquisadoras (primeiras autoras deste artigo) em suas próprias salas de aula, em uma escola pública do interior do estado de São Paulo, sendo uma de $1^{\circ}$ ano e outra de 3 ano do ensino fundamental.

Naturma do $1^{\circ}$ ano havia 31 crianças matriculadas e na data de desenvolvimento do projeto a sala contava com 27 alunos frequentes. A turma do $3^{0}$ ano do ensino fundamental era composta por 25 alunos regularmente matriculados.

As atividades foram aplicadas em cada turma pela própria professora, que desenvolveu as aulas considerando as três etapas para uma aula sobre resolução de problemas, conforme a proposta de Van de Walle (2009):

1므 fase - Antes: preparar os alunos, realizar a leitura, verificar se o problema foi compreendido, ativar os conhecimentos prévios necessários.

2 ${ }^{\text {a }}$ fase - Durante: alunos trabalhando, geralmente em duplas ou trios, construindo a sua resolução com a mediação da professora, quando necessária. 
BORTOLUCCI, Marina de Souza; CHIARELLO, Paula Cristina; ALMEIDA, Alessandra Rodrigues de; MEGID, Maria Auxiliadora Bueno Andrade

3a fase - Depois: alunos debatendo, discutindo e justificando as várias soluções para o problema trabalhado. Essa fase pode ser entendida como um processo de interação, em que ocorre a partilha de significados entre os indivíduos durante as discussões coletivas nas quais os alunos argumentam, defendem as suas ideias e questionam as ideias dos colegas.

As situações-problema não convencionais aplicadas foram selecionadas pelas professoras-pesquisadoras após o estudo dos aportes teóricos sobre o tema e de análises de diferentes materiais didáticos. Buscaram, sobretudo, situações desafiadoras e que apresentassem uma estrutura textual não convencional, mobilizando os alunos na busca de estratégias para além do uso direto de um algoritmo e permitindo a elaboração de hipóteses diversificadas.

Em virtude das especificidades das turmas, cada professora-pesquisadora selecionou cinco diferentes tipos de problemas para serem aplicados.

Neste artigo, focamos os resultados de duas dessas situações-problema, as discussões advindas desse trabalho, as percepções dos alunos e as ações das professoras.

Os instrumentos utilizados para a produção dos dados foram os registros realizados pelos alunos nas folhas das situações-problema, os registros das suas exposições orais, durante a segunda e a terceira fase de cada aula - conforme anteriormente descrito -, e as observações e registros das professoras-pesquisadoras.

\section{A RESOLUÇÃO DE PROBLEMAS COM A TURMA DO 1ํ ANO}

As crianças da turma do $1^{0}$ ano encontravam-se na fase inicial da alfabetização, em processo de construção do sentido numérico, e ainda não tinham contato com situações-problema convencionais, não possuindo, portanto, um modelo de situação-problema como referência única, como é comum se observar em alunos que estão em anos escolares mais avançados. Porém, percebemos, ao longo do desenvolvimento da pesquisa, que os alunos esperavam acertar sempre. Temiam errar, além de, muitas vezes, adotarem a postura de esperar que a professora dissesse o que e como fazer para solucionar o problema.

0 primeiro problema escolhido para ser analisado neste artigo caracteriza-se por possuir mais de uma solução possível: Três homens caíram de um barco, mas apenas dois deles ficaram com os cabelos molhados. Por quê? (autor desconhecido) 
As crianças foram organizadas em duplas para facilitar a troca de ideias e receberam a situação-problema em folha escrita. A professora-pesquisadora realizou a leitura da situação-problema algumas vezes e, como a maioria da turma ainda não escrevia alfabeticamente, combinou-se que a professora seria a escriba da turma, registrando na lousa as hipóteses levantadas. Tais aspectos são aqueles considerados por Van de Walle (2009) como os necessários na 1a fase, Antes.

Após certificar-se de que os alunos compreenderam o problema, a professora destinou um momento para que conversassem em duplas sobre a solução. Quando solicitada, passava pelas duplas, mediando as discussões. Essa fase é a denominada por Van de Walle (2009|) como a fase Durante, ou 2a fase.

Ao perceber que todos haviam pensado e discutido sobre as possíveis soluções, a professora passou a fazer o registro das respostas dos alunos na lousa.

Profa..: Então, pessoal! Vamos lá! Eu vou registrar a resposta de cada dupla aqui na lousa e depois discutimos.

N.: Eu acho que um homem não caiu na água, caiu na areia e os outros dois caíram na água.

R.: Porque aquele que não molhou o cabelo ficou com a cabeça para fora da água.

L.: O homem que não molhou o cabelo... ele caiu em pé e os outros dois caíram deitados, aí molharam o cabelo.

A.Lu.: Eu acho que um homem era careca, ele não tinha cabelo!

A.C.: É! Ou ele usava touca de banho, igual na natação.

A professora registrou as respostas na lousa. Após a releitura de todas elas, algumas crianças contestaram algumas respostas, como a de L., justificando que, mesmo caindo em pé, espirraria água e molharia o cabelo. Também a de N., pois não achavam possível um dos homens cair na terra e os outros na água. Cada criança defendeu sua resposta, descrevendo o que imaginou. A turma se manifestou satisfeita com as hipóteses levantadas. Neste momento, uma criança perguntou:

A.La.: Mas professora, qual é a resposta certa?

A professora questionou a turma sobre o que achavam a respeito da pergunta de A.La. e algumas crianças citaram uma ou outra resposta como a certa. Mas A.C. argumentou:

A.C.: Não dá para saber qual é a certa, não é, professora? Porque tudo que a gente falou está certo! 
A análise das respostas dos alunos permite afirmar que todos buscaram um meio de explicar o porquê de um homem não ter molhado o cabelo. As respostas que geraram maiores dúvidas ou pareceram menos convincentes foram debatidas em grupo, sendo que os próprios alunos argumentaram sobre suas proposições e os diferentes pontos de vista nelas envolvidos. Tal situação revelou que a atividade efetivamente permitiu diferentes soluções e se configurou como uma potente estratégia para propiciar que os alunos explicassem e justificassem suas resoluções, considerando diferentes hipóteses e raciocínios (BOAVIDA; MENEZES, 2012).

O segundo problema trabalhado com o $1^{0}$ ano escolhido para ser analisado neste artigo foi o seguinte: "O meu avô cria no quintal do sítio porcos e galinhas. Ontem, quando fui visitá-lo, contei no quintal 5 cabeças e 14 pés de animais. Quantos porcos e quantas galinhas estavam no quintal do meu avô?" Apesar de ser uma situação-problema de resposta única, foge das propostas convencionais.

A professora fez a leitura do problema várias vezes. Elaborou em seguida um registro pictórico na lousa, desenhando uma cabeça com o número 5 , o desenho de um pé com o número 14 em frente, um porco e uma galinha com pontos de interrogação. Na sequência, leu mais uma vez o problema, apontando para as informações na lousa. Adotou esse procedimento porque as crianças ainda não conseguiam retomar o problema sozinhas - $1^{\text {a }}$ fase Antes (VAN DE WALLE, 2009).

Muitas crianças tiveram dificuldade para compreender o problema, pois desenhavam cinco porcos e cinco galinhas. A professora retomou a questão com o grupo e, após nova discussão, os alunos concluíram que havia no total cinco animais, porque havia cinco cabeças e era preciso então descobrir, dentre esses cinco, quantos eram galinhas e quantos eram porcos. Após esse momento, os alunos tiveram novamente mais um tempo da aula para conversar e elaborar registros de resolução - 2a fase - Durante (VAN DE WALLE, 2009).

Ao observar as duplas em atividade foi possivel perceber que a maior parte dos alunos conseguiu chegar à resolução por tentativa e erro. Muitos desenharam as cinco cabeças, deixando algumas para porcos e outras para galinhas, sem atentar para a questão da quantidade de pés, como é possível verificar no exemplo a seguir. A professora, tentando compreender a produção de uma aluna, questionou: 
Prof. $\underline{a}$ : A.C., como você pensou?

A.C.: Eu descobri que tem três porcos e duas galinhas! Porque três mais dois dá cinco!

Prof. : : Muito bem pensado. Mas e os pés? Têm 14?

A criança A.C. retomou seu registro e realizou a contagem de pés, descobrindo que havia 16 em seu desenho. A professora questionou:

Prof. -. 0 que você pode fazer para que tenha apenas 14 pés?

A professora deixou a criança pensando e, quando retornou, verificou o seguinte registro:

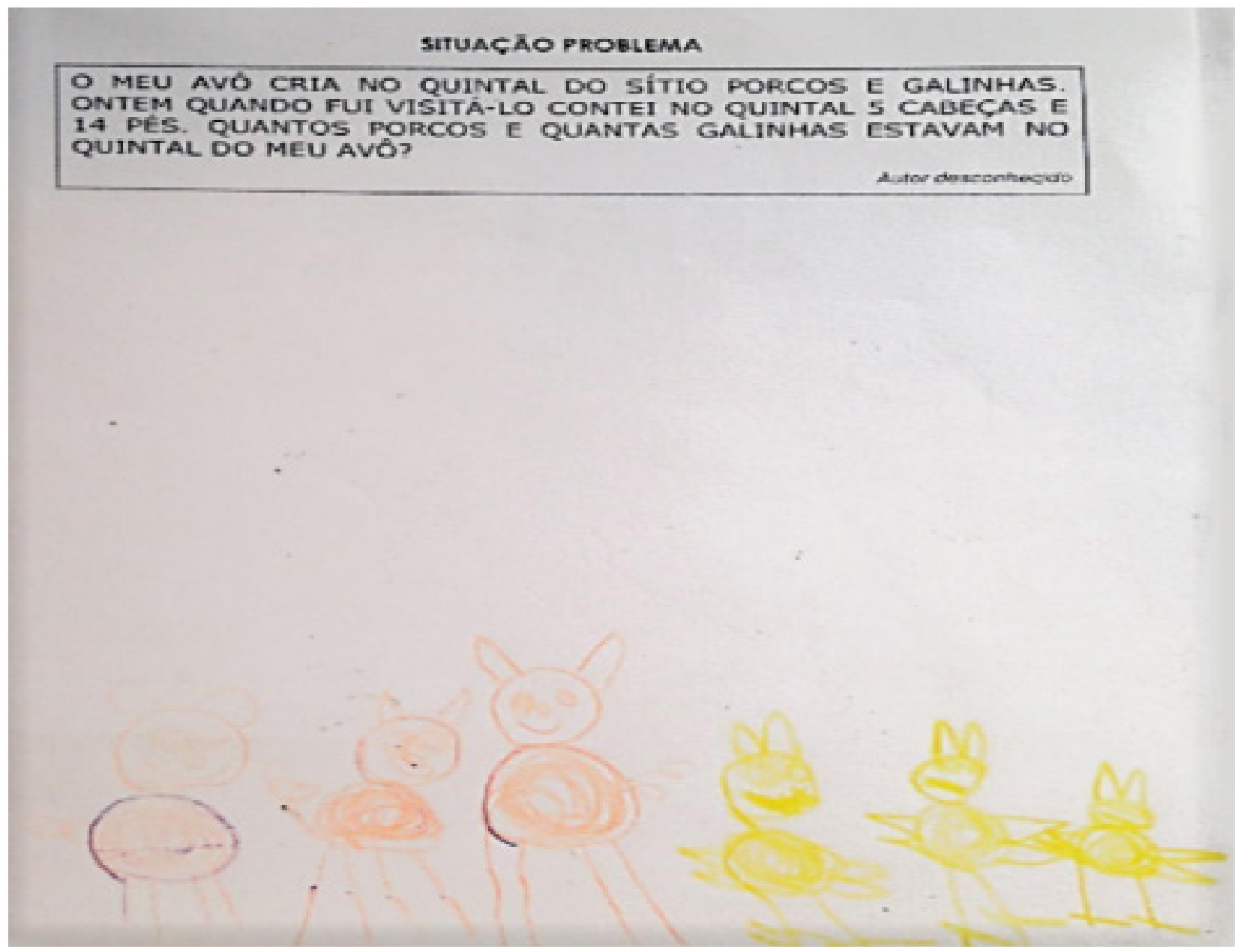

Prof.. : 0 que você fez para resolver o problema dos pés?

A.C.: Eu troquei um porco (como é possível perceber no desenho pelas marcas do lápis de cor) por uma galinha, porque a galinha tem menos pés que o porco!

A professora solicitou que a criança contasse novamente os pés. Como dessa vez as informações batiam com o enunciado, A.C. percebeu que havia chegado à resposta correta sem a necessidade da confirmação da professora. 
BORTOLUCCI, Marina de Souza; CHIARELLO, Paula Cristina; ALMEIDA, Alessandra Rodrigues de; MEGID, Maria Auxiliadora Bueno Andrade

O mesmo aconteceu com a criança E., que, em vez de apagar o porco, optou por fazer um $\mathrm{X}$, anulando o animal, como podemos ver na imagem a seguir:

SITUACAO PROBLEMA
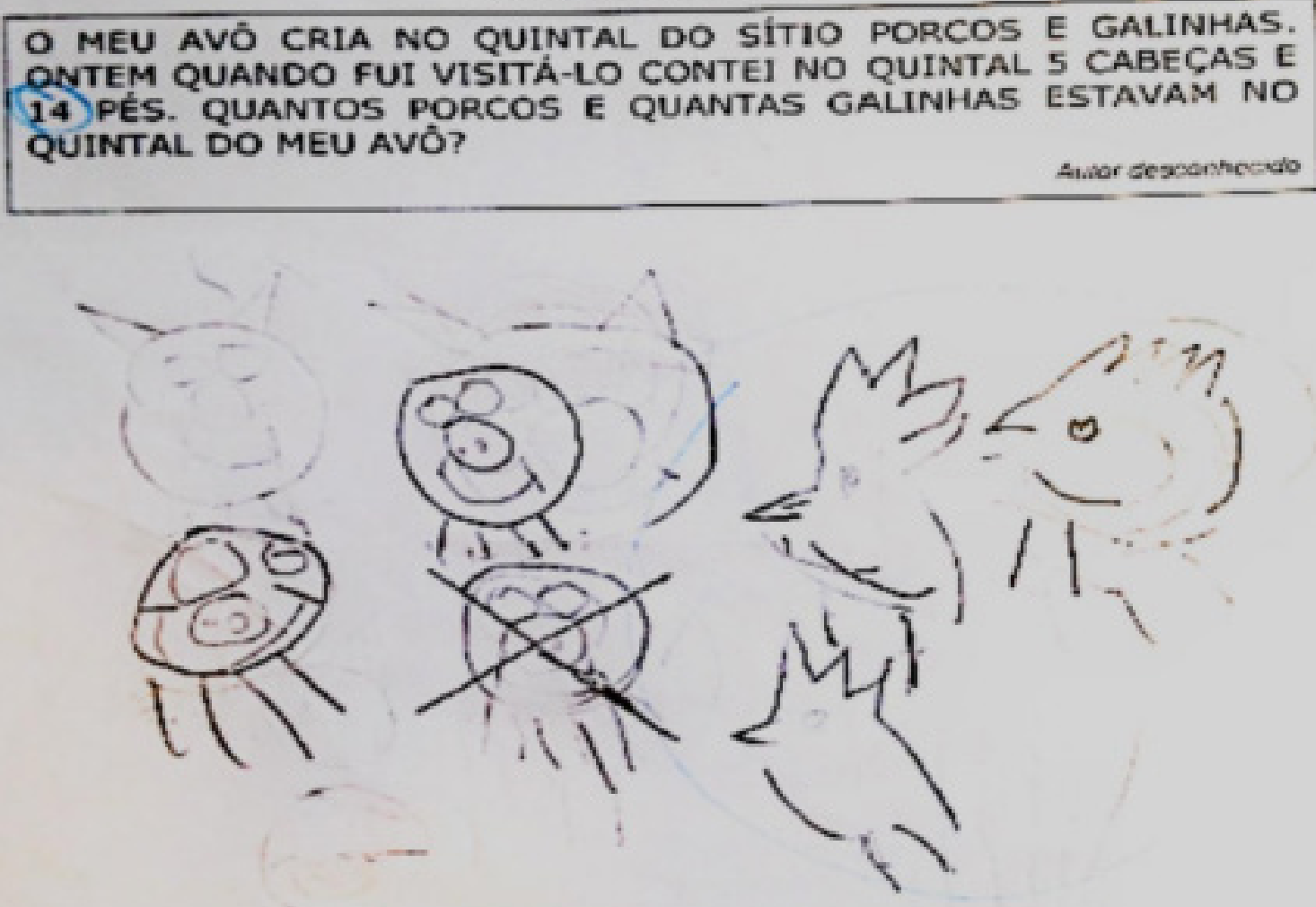

$O$ registro de $\mathrm{E}$. mostra que a aluna não sentiu a necessidade de desenhar 0 animal completo, apenas a cabeça (identificando qual dos animais seria) e risquinhos para os pés (quatro ou dois, dependendo do animal).

Alguns alunos chegaram à resposta rapidamente, pois optaram por desenhar os animais intercalados, iniciando pela galinha (galinha/porco/galinha/ porco/galinha). Dessa maneira, ao conferirem o número de pés, percebiam que tinham chegado à resolução correta.

Foi o que ocorreu com A.La., que optou por desenhar uma cabeça de cada animal sem verificar a quantidade de pés, satisfazendo-se com a quantidade de cabeças. No entanto, quando questionada pela professora sobre a quantidade de pés relacionada ao problema, A.La. acrescentou risquinhos que representassem a quantidade de pés de cada cabeça, como é possível observar no registro a seguir. 


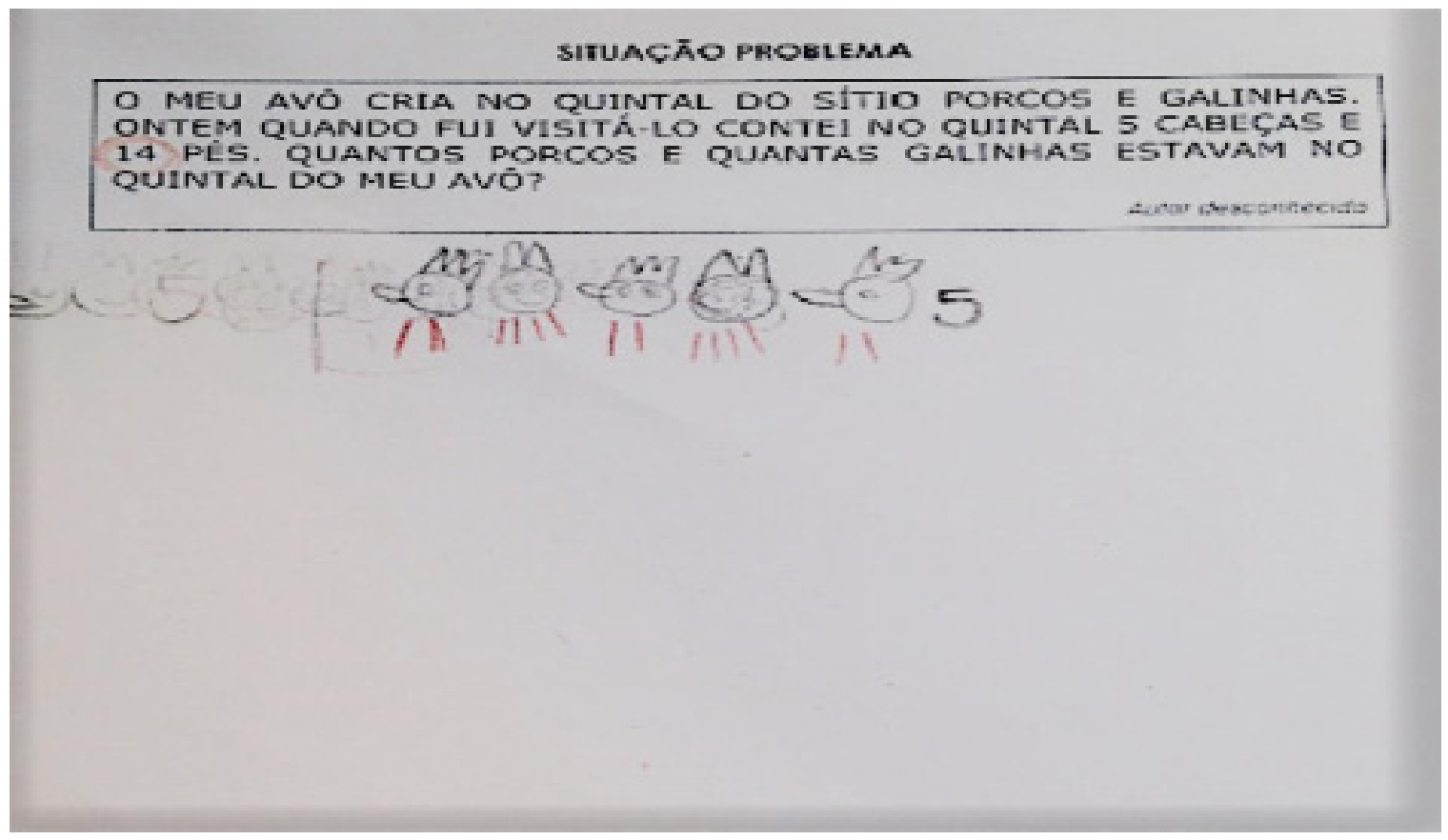

$\mathrm{O}$ registro de $\mathrm{K}$. revela que a aluna soube organizar as informações do problema, tornando perceptível seu raciocínio:

\section{SITUACĀO PROBLEMA}

O MEU AVÓ CRTA NO QUINTAL DO SITIO PORCOS E GALINHAS. ONTEM QUANDO FUT VISITÁ-LO CONTET NO QUTNTAL 5 CABECAS E 34 pES QUANTOS PORCOS E QUANTAS GALINHAS ESTAVAM NO QUINTAL DO MEU AVÓ?
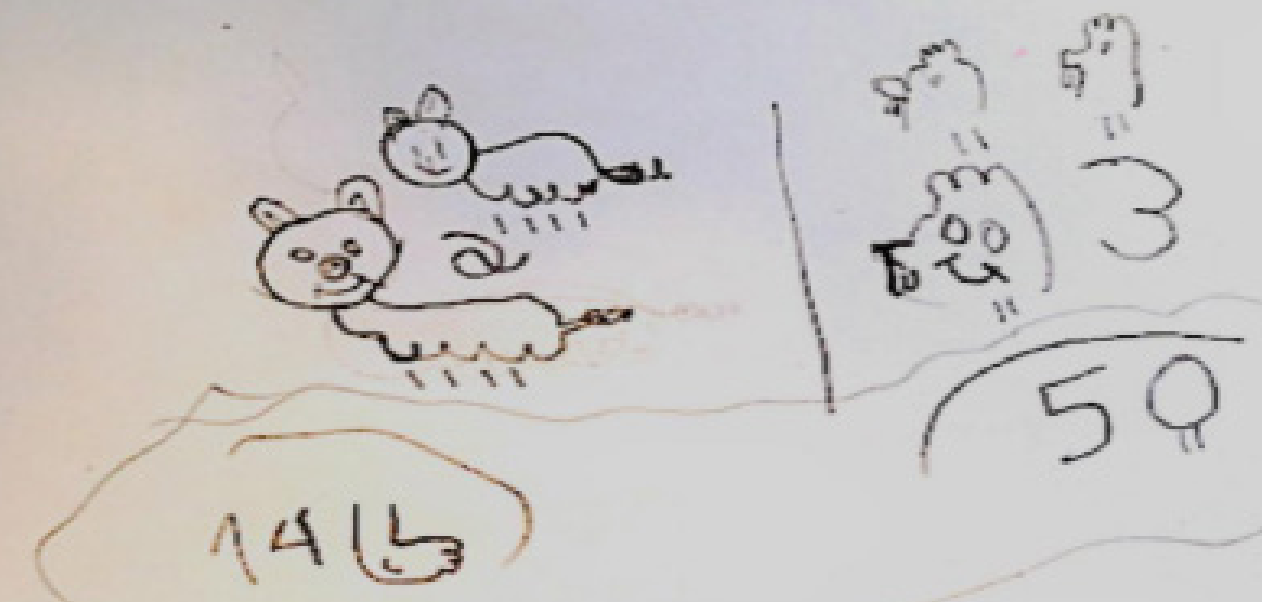

As respostas e registros apresentados revelam que os alunos mobilizaram diferentes estratégias para solucionar o problema. Os registros envolveram representações pictóricas e matemáticas com o intuito de darem sentido 
BORTOLUCCI, Marina de Souza; CHIARELLO, Paula Cristina; ALMEIDA, Alessandra Rodrigues de; MEGID, Maria Auxiliadora

às soluções, identificarem os elementos presentes na situação-problema e destacarem os dados que lhes pareciam relevantes.

A partir do trabalho com os problemas "não tradicionais" e com a utilização de diferentes tipos de registros, os alunos sentiram-se motivados a discutir os problemas, realizando uma efetiva participação ativa junto ao grupo e uma busca de procedimentos para resolução.

Não foi possível esperar que todas as crianças chegassem ao resultado, pois as que resolveram rapidamente começaram a se dispersar e, por isso, a professora decidiu partir para a socialização dos registros. Essa etapa teve um significado diferente para essa situação-problema, principalmente para o aluno Ka., que, assim como a aluna A.C., chegou à resposta três porcos e duas galinhas. Mas quando a professora questionou a respeito da quantidade de pés, que não correspondia a 14, embora tenha persistido, não conseguiu chegar à solução de trocar um porco por uma galinha.

Durante a socialização do registro de A.C., o aluno Ka. exclamou:

Ka.: Ah! Agora entendi o que está errado no meu! Eu também preciso trocar um porco por uma galinha!

O registro do aluno Ka. ficou da seguinte maneira:

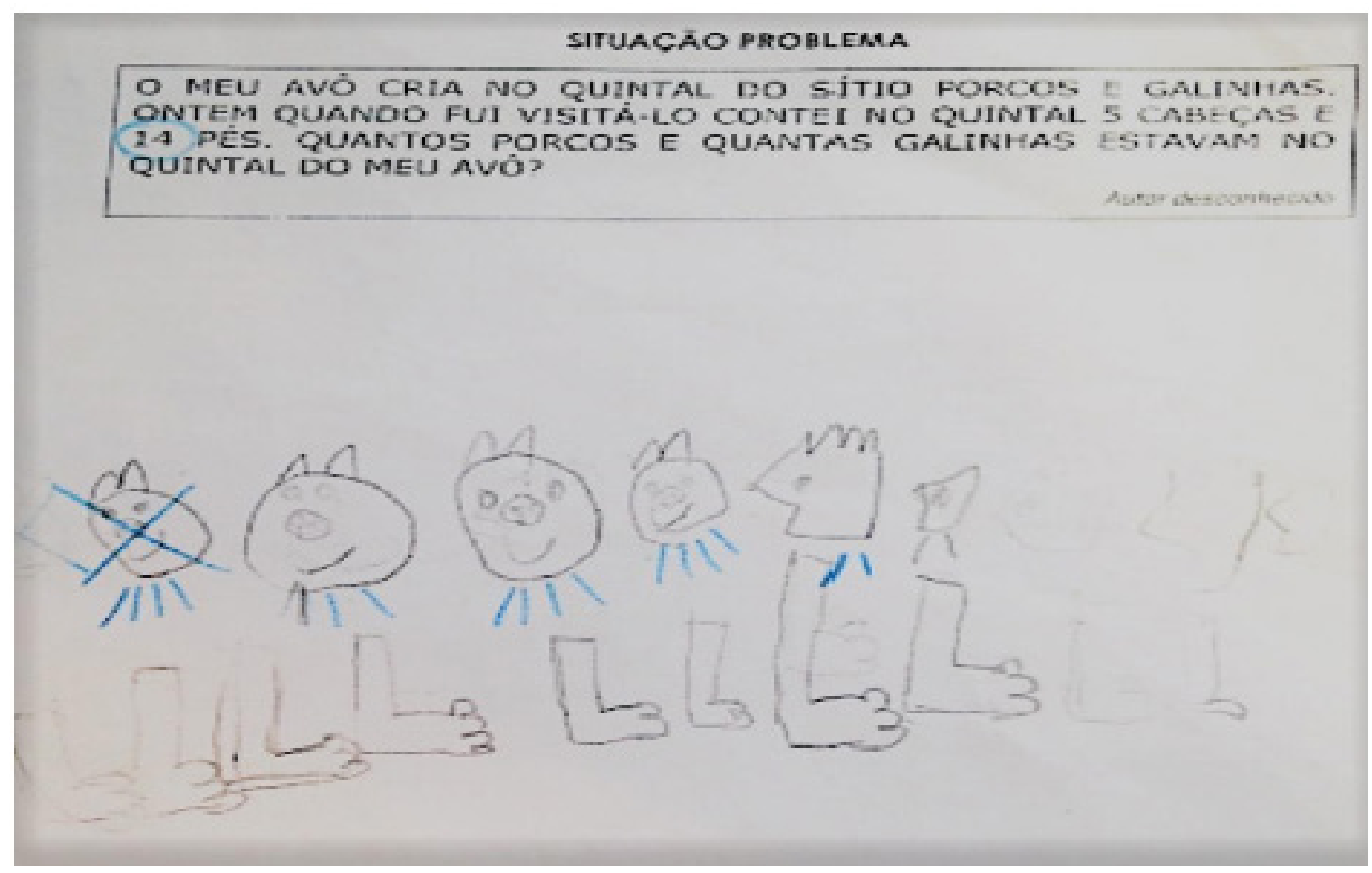


Nesse sentido, evidencia-se a importância do momento de socialização indicado como Depois (VAN DE WALLE, 2009). A socialização foi essencial para que Ka. conseguisse perceber seu equívoco e encontrasse a solução adequada para o problema. Esse momento de interação entre os alunos e entre alunos e professor possibilitou a Ka. a compreensão do problema a partir da negociação de significados matemáticos para sua solução.

A RESOLUÇÃO DE PROBLEMAS COM A TURMA do 3ํanO

Na turma do 3ำ ano, a maioria dos alunos não dominava o uso dos algoritmos, uma vez que as técnicas ainda não haviam sido apresentadas de maneira sistemática. O conhecimento que tinham sobre algoritmos era decorrente dos estudos no ano anterior ou de experiências extraescolares. Os alunos desta turma estavam finalizando o ciclo de alfabetização e por isso nem todos realizavam a leitura de forma autônoma e fluente. A professora-pesquisadora realizou a leitura em voz alta de cada situação-problema visando a compreensão efetiva da tarefa, ações que consideramos comporem a $1^{a}$ fase - Antes (VAN DE WALLE, 2009).

A professora, tal qual o realizado na turma do $1^{0}$ ano, apresentou o primeiro problema: Três homens caíram de um barco, mas apenas dois deles ficaram com os cabelos molhados. Por quê? (autor desconhecido). Repetiu a leitura algumas vezes. Em seguida, organizados em duplas e negociando a resolução com seus pares, foram organizando suas decisões.

Enquanto observava a discussão das crianças, a professora deparou com o seguinte registro de um aluno: $3-2=1$. Ao ser indagado pela professora sobre como estava pensando, o aluno afirmou que tentava explicar para sua colega o problema. A professora então perguntou se a resposta dessa conta satisfazia a pergunta do problema. 0 aluno pensou, percebeu que não, apagou o registro e começou a buscar outra forma para solucionar o problema.

As duplas foram orientadas no sentido de que poderiam responder à questão com registro escrito ou pictórico, ficando a critério de cada uma a melhor forma. No momento de apresentar as soluções encontradas, durante a socialização, as duplas expuseram oralmente suas propostas e a professora registrava na lousa. Houve várias respostas parecidas, sendo algumas bem criativas:

"Porque um deles ficou com a cabeça erguida e os outros caíram de maduro." “Um mais esperto pulou na ponta do barco e pulou na ilha.” 
"Os dois caíram de cabeça para baixo. O que não molhou o cabelo caiu com a prancha."

As outras respostas seguiam a linha de raciocínio na qual dois homens caíram de cabeça para baixo e um caiu de pé ou de cabeça erguida.

Após as apresentações dos alunos, a professora resolveu apresentar a sua resposta para o problema. A turma ficou muito ansiosa para ouvir e a professora falou que havia pensado na possibilidade de um dos homens ser careca e por isso não teria cabelo para molhar. Os alunos ficaram surpresos e acharam que essa era a resposta correta, uma vez que foi apresentada pela professora. Discutiu-se a respeito disso, sobre cada um ter uma resposta diferente e que todas poderiam estar corretas, pois respondiam de forma coerente à pergunta.

Para o $3^{\circ}$ ano, o texto do segundo problema foi modificado, porém mantendo a ideia central: "O seu Chico, avô de Godofredo, cria no quintal do sítio cabras e galinhas. Nas férias, quando Godofredo foi visitá-lo, contou no quintal 7 cabeças e 20 pés de animais. Quantas cabras e quantas galinhas estavam no quintal do seu Chico?”.

A professora fez a leitura do problema algumas vezes. No entanto, considerou que seria importante deixar um momento para que os alunos buscassem compreender os dados do problema. Num primeiro momento, as crianças encontraram muita dificuldade para compreender o texto do problema - elas não entenderam imediatamente as informações. Para muitos, não parecia estar claro que a quantidade total de animais era sete, pois foi observado que desenhavam sete cabeças de cabras e depois sete cabeças de galinhas.

Para favorecer a compreensão das informações necessárias para encontrar uma solução, a professora optou por realizar alguns questionamentos para a turma, como: "quantas cabeças sabemos que tem no sítio?”; “nós sabemos quantas pertencem a cada animal?”; “qual é o número de patas?” e "quantas patas tem cada animal citado?”.

Conforme os alunos compreendiam essas informações, sentiam-se mais confiantes para desenvolver uma estratégia de solução. Com essas considerações, descrevemos o que julgamos ser a 1a fase - Antes, de acordo com Van de Walle (2009).

Na sequência, os alunos foram orientados a conversar sobre o problema e a elaborar o registro do modo que considerassem adequado. A professora 
observava a interação entre as duplas, fazendo intervenções quando solicitada e nas situações que considerasse oportunas.

Algumas estratégias utilizadas pelos alunos foram: colocar a quantidade total de pés com risquinhos e depois circular a quantia pertencente a cada animal, bem como desenhar a quantia dos pés e das cabeças, depois distribuindo, ligando os pés às cabeças. Outros ainda desenharam as cabeças e foram alternando a distribuição dos pés entre cabras e galinhas.

Como os alunos ainda não dominavam as técnicas operatórias dos algoritmos, mostravam-se mais dispostos a solucionar a situação-problema utilizando outras formas de resolução. Nesse sentido, foi possível observar que a exigência precoce pelo uso do algoritmo poderia dificultar tanto a compreensão como a resolução do problema, pois os alunos estariam buscando uma “conta” para solucionar a questão (CAVALCANTI, 2001).

Uma aluna conseguiu responder rapidamente. Desenhou sete círculos para as cabeças e colocou, de forma alternada, os números 2 e 4 para representar as patas dos animais. Com esse procedimento, ela acertou a resposta na primeira tentativa. Porém, para conferir o resultado, fez risquinhos para representar a quantidade e conseguir somar os números de pés. Considerase que esta aluna ainda precisa avançar nas suas estratégias de soma, pois demonstra que não conserva quantidades. A imagem contempla o registro descrito anteriormente.

O seu Chico, avó de Godofredo cria no quintal do sitio cabras e galinhas. Nas ferrias, quando Godofredo fot visita-lo contou no quintal 7 cabeças e 20 pés. Quantas cabras e quantas galinhas estavam no quintal do seu Chico?

\section{0 2424242 \\ 1}

\section{$11+111+11+111+11+111+11=20$}


No final da atividade, cinco alunos não conseguiram chegar a uma solução possível para o problema e outros cinco necessitaram de vários momentos de mediação com a professora para encontrar uma resposta.

Como parte da metodologia da aula, os alunos socializaram com os demais colegas sobre qual estratégia utilizaram para responder à pergunta, registrando na lousa o caminho encontrado para que todos conhecessem outras soluções possíveis.

Após a aplicação dessa situação-problema, ficou evidente que a fase Antes, proposta por Van de Walle (2009), foi muito importante para o bom desenvolvimento da aula. Nesse momento é possível ao professor verificar se o problema foi totalmente compreendido pelo aluno. Realizar perguntas diretas, relacionadas ao texto do problema, auxilia na compreensão das informações. A partir disso, os alunos conseguem trabalhar melhor na resolução do problema. Caso a professora não tivesse realizado tal intervenção, o desempenho dos alunos poderia ter ficado aquém do esperado.

Outro momento também muito importante é o Depois (VAN DE WALLE, 2009), quando os alunos são convidados a explicar suas produções e os raciocínios envolvidos nas diferentes estratégias de resolução. Este se configura como um momento complexo da aula. Afinal, são muitos os desafios enfrentados pelo docente no sentido de que possa contribuir para a apropriação dos conhecimentos matemáticos pelos alunos e para a sustentação da apresentação e de justificativas das ideias matemáticas envolvidas no processo de resolução de problemas (BOAVIDA; MENEZES, 2012). Tais considerações colocam em destaque a importância do preparo e acompanhamento do professor para que a fase Depois (VAN DE WALLE, 2009) seja matematicamente produtiva.

\section{CONSIDERAÇÕES FINAIS}

O desenvolvimento desta pesquisa com as crianças permitiu observar que o trabalho com situações que efetivamente se configuram como problemas possuem grande potencial para a aprendizagem matemática dos alunos, ainda que tais situações não envolvam números e registros exclusivamente numéricos.

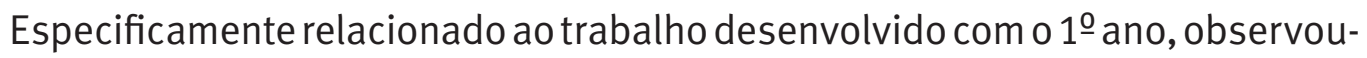
se que, mesmo sendo o primeiro contato dos alunos com a matemática formal/ escolar, muitos apresentavam o medo de errar e a concepção de que todo 
problema tem uma única solução. Também se observou, num momento inicial, uma relação de passividade diante da tarefa e a espera de que a professora apontasse como deveriam proceder.

A turma do $3^{0}$ ano entendia inicialmente que a resolução dos problemas deveria ocorrer pela utilização de algum algoritmo e/ou pela apresentação de um resultado numérico. A possibilidade de realizar outros tipos de registros trouxe maior significado da matemática para os alunos.

O contexto de sala de aula das duas turmas evidenciou a necessidade de se criar um ambiente de aprendizagem que possibilitasse o início de uma nova postura dos alunos diante dos desafios propostos. Após essa experiência, passaram a demonstrar maior confiança em arriscar, testar hipóteses, interpretar de forma lógica e investigativa as diferentes situações apresentadas.

Dessa forma, as relações que essas turmas começaram a construir com a matemática mostraram-se muito positivas. Ampliaram tais ações para outros momentos, para além dessa disciplina. Entendemos que, quando o aluno torna-se protagonista de sua aprendizagem, sente liberdade para apresentar seu raciocínio e estratégias pessoais, transformando a sala de aula em um espaço de trocas, onde todos contribuem com o avanço coletivo.

Ao utilizar como metodologia os três momentos (antes, durante e depois) propostos por Van de Walle (2009), foi possível assegurar um ambiente de aprendizagem marcado pela relação dialógica entre professor e aluno. De maneira especial, isso ocorre quando a voz dos alunos é respeitada, quando são ouvidos e suas estratégias são valorizadas para além do decreto de estarem "certas ou erradas", possibilitando uma atividade matemática na qual a comunicação e a produção de significados sejam centrais (NACARATO; MENGALI; PASSOS, 2009).

A metodologia propiciou ainda um ambiente de aprendizagem no qual os alunos refletiram sobre as diferentes estratégias utilizadas, criaram registros matemáticos significativos para si próprios, os quais facilitaram a comunicação com os demais colegas nos momentos em que eram convidados a explicar o raciocínio utilizado para a resolução do problema, rompendo com uma postura passiva perante situações que não oferecem desafios.

O ensino por meio da resolução de problemas possibilitou um novo posicionamento das professoras-pesquisadoras ante a aprendizagem dos alunos. Perceberam que tais ações ampliaram a compreensão de que 0 docente tem um papel ativo na aprendizagem do aluno. Ainda, que cabe 
ao professor mediar os diferentes momentos da aula, proporcionando tempo para a discussão entre os alunos, sabendo ouvi-los, questionandoos adequadamente, estabelecendo uma relação dialógica na qual aluno e professor respeitem as estratégias apresentadas, sem que estas sejam consideradas apenas certas ou erradas.

Por fim, a pesquisa contribuiu de maneira significativa para a formação das professoras, possibilitando a articulação entre teoria e prática, o desenvolvimento da escuta sensível em relação às crianças, percebendo que elas dão grandes indícios e caminhos para o replanejamento das aulas em busca dos objetivos pedagógicos, tornando-as protagonistas nesse processo tão belo e prazeroso que é a aprendizagem. 


\section{Unconventional problems: problem-solving strategies for students in the early years of primary education}

Abstract: This article aims to discuss problem-solving as a strategy for Mathematics classes at three different points - before, during and after the activity is proposed - in two different settings - a 1st grade and a 3rd grade class of primary education at a public school in a city in the state of São Paulo. Data were collected from records made by the students, as well as videorecordings of classes where the activities were conducted. This study is of a qualitative nature as it considered the description and analysis of classroom interactions. Results show that working on situations that may actually be considered problems has a great potential for teaching Mathematics, and that the methodology used ensured a learning environment marked by teacherstudent dialogue.

Keywords: Mathematical education. Primary education. Problem-solving. 


\section{Problemas no convencionales: estrategias de resolución de problemas de alumnos de los años iniciales la enseñanza \\ básica}

Resumen: Este artículo tiene el objetivo de discutir la resolución de problemas como estrategia para las clases de matemáticas considerando tres momentos: el antes, el durante y el después de la propuesta, en una clase del 1.er año y una del 3.er año de la enseñanza básica de una escuela de la red pública del interior de São Paulo. Los datos se tomaron a partir de registros de los alumnos y de videograbaciones de las clases mientras las actividades se realizaban. La investigación se desarrolló desde una perspectiva cualitativa, valorando la descripción y el análisis de las interacciones en las clases. Los resultados indicaron que el trabajo con situaciones que realmente se constituyen como problemas posee un gran potencial de aprendizaje matemático para los alumnos, y que la metodología utilizada permite asegurar un ambiente de aprendizaje marcado por la relación dialógica entre profesor y alumno.

Palabras clave: Educación matemática. Enseñanza básica. Resolución de problemas. 


\section{REFERÊNCIAS}

ABRANTES, Paulo. Um (bom) problema (não) é (só). Educação e Matemática, v. 8, p. $7-10,1989$.

ALVARENGA, Dina; VALE, Isabel. A exploração de problemas de padrão: um contributo para o desenvolvimento do pensamento algébrico. Quadrante, XV, v. 1, p. 27-55, 2007.

BOAVIDA, Ana Maria; MENEZES, Luís. Ensinar matemática desenvolvendo as capacidades de resolver problemas, comunicar e raciocinar: contornos e desafios. In: CANAVARRO, Ana Paula et al. Investigação em educação matemática: práticas de ensino da matemática. Portugal: Portalegre Spiem, 2012.

BRASIL. Secretaria de Educação Fundamental. Parâmetros Curriculares Nacionais: introdução aos Parâmetros Curriculares Nacionais - Secretaria de Educação Fundamental. Brasília: MEC/SEF, 1998.

CAMPINAS. Prefeitura Municipal. Diretrizes Curriculares da Educação Básica para o Ensino Fundamental. Anos iniciais: um processo contínuo de reflexão e ação. Campinas: Secretaria Municipal de Educação, 2012.

C NDIDO, Patrícia Teresinha. Comunicação em matemática. In: SMOLE, Kátia Stocco; DINIZ, Maria Ignez (Org.). Ler, escrever e resolver problemas: habilidades básicas para aprender matemática. Porto Alegre: Artmed, 2001.

CAVALCANTI, Cláudia Tenório. Diferentes formas de resolver problemas. In: SMOLE, Kátia Stocco; DINIZ, Maria Ignez (Org.). Ler, escrever e resolver problemas: habilidades básicas para aprender matemática. Porto Alegre: Artmed, 2001.

DÍAZ, Maria Verónica; POBLETE, Álvaro. Contextualizando tipos de problemas matemáticos en el aula. Números, v. 45, p. 33-41, mar. 2001.

DINIZ, Maria Ignez. Resolução de problemas e comunicação. In: SMOLE, Kátia Stocco; DINIZ, Maria Ignez. Ler, escrever e resolver problemas: habilidades básicas para aprender matemática. Porto Alegre: Artmed, 2001.

NACARATO, Adair Mendes; MENGALI, Brenda Leme da Silva; PASSOS, Cármen Lúcia Brancaglion. Um ambiente para ensinar e aprender matemática. In: A matemática nos anos iniciais do ensino fundamental: tecendo fios do ensinar e do aprender. Belo Horizonte: Autêntica, 2009. 
ONUCHIC, Lourdes de La Rosa. Ensino-aprendizagem de matemática através da resolução de problemas. In: BICUDO, Maria Aparecida Viggiani (Org.). Pesquisa em educação matemática: concepções \& perspectivas. São Paulo: Editora Unesp, 1999.

ONUCHIC, Lourdes de La Rosa; ALLEVATO, Norma Suely Gomes. Novas reflexões sobre o ensino-aprendizagem de matemática através da resolução de problemas. In: BICUDO, Maria Aparecida Viggiani; BORBA, Marcelo de Carvalho (Org.). Educação matemática: pesquisa em movimento. 2. ed. São Paulo: Cortez, 2005.

; _______. Pesquisa em resolução de problemas: caminhos, avanços e novas perspectivas. Boletim de Educação Matemática, v. 25, n. 41, p. 73-98, dez. 2011.

STANCANELLI, Renata. Conhecendo diferentes tipos de problemas. In: SMOLE, Kátia Stocco; DINIZ, Maria Ignez. Ler, escrever e resolver problemas: habilidades básicas para aprender matemática. Porto Alegre: Artmed, 2001.

VAN de WALLE, John. A. Ensinando pela resolução de problemas. In: VAN de WALLE, John. A. Matemática no ensino fundamental: formação de professores e aplicação em sala de aula. Porto Alegre: Artmed, 2009.

VILA, Antoni; CALLEJO, María Luz. Pensar na aula de matemática? In: VILA, Antoni; CALLEJO, María Luz. Matemática para aprender a pensar: o papel das crenças na resolução de problemas. Porto Alegre: Artmed, 2006.

\section{SOBRE OS AUTORES}

Alessandra Rodrigues de Almeida é doutora em Ensino de Ciências e Matemática pela Universidade Estadual de Campinas. Atualmente é docente da Faculdade de Educação da Pontifícia Universidade Católica de Campinas (PUC-Campinas).

E-mail: alessandra.almeida@puc-campinas.edu.br

Maria Auxiliadora Bueno Andrade Megid é doutora em Educação. Atualmente é professora titular da Faculdade de Educação da Pontifícia Universidade Católica de Campinas (PUC-Campinas).

E-mail:dmegid@puc-campinas.edu.br 
Marina de Souza Bortolucci é especialista em Ensino de Ciências e Matemática. Atualmente é professora da Rede Municipal de Campinas.

E-mail para contato: bsaniram@yahoo.com.br

Paula Cristina Chiarello é especialista em Ensino de Ciências e Matemática. Atualmente é professora da Rede Municipal de Campinas.

E-mail para contato: pchiarello.p@gmail.com

Recebido em: abril de 2018

Aprovado em: maio de 2018 